\title{
Managers' Characteristics: Results from an Exploratory Comparison of Young Managers in Bulgaria and USA and its Implications for Management Education in Bulgaria*
}

\author{
Nils-Erik Aaby / Marin Marinov / Svetla Marinova**
}

This paper explores managerial characteristics of young Bulgarian and U.S. managers by identifying differences between the two samples in terms of risk taking, reliance on others, leadership style, use of intelligence and cooperation. A number of reasons accounting for significant differences are discussed, suggestions for the content and approaches to management education in Bulgaria are presented.

Der vorliegende Artikel untersucht charakteristiken von jungen Managern in Bulgarien und den USA. Unterschiede zwischen den beiden Gruppen in Bezug auf Risikobereitschaft, Abhängigkeit von anderen, Führungsstil, Einsatz von Intelligenz und Kooperationsverhalten werden untersucht. Eine Reihe von Gründen die für signifikante Unterschiede sprechen werden diskutiert. Darüber hinaus werden Vorschläge für mögliche Ansätze und Inhalte einer Managerausbildung in Bulgarien vorgestellt.

Manuscript received: 18.8.96, accepted: 15.1 .97

** Nils-Erik Aaby, born 1947 in Norway, Associate Professor of Marketing and International Business, College of Business, University of Colorado at Colorado Springs, U.S.A. Major areas of research interest: international business, international marketing, business to business marketing, comparative management.

Marin Marinov, born 1948, Professor of Marketing, Technical University of Sofia, Bulgaria. In 1996/1997 Visiting Professor of Marketing and International Business at the University of Colorado at Colorado Springs, U.S.A. Major areas of research interest: international business, international marketing, privatisation related changes in company marketing, management and marketing change in Central and Eastern Europe.

Svetla Marinova, born 1962, MBA (Warwick), Ph.D. student funded by Phare ACE Programme at Aston University, UK. Major areas of research interest: international marketing, market orientation, marketing and management changes in Central and Eastern Europe. 


\section{Introduction}

The characteristics of the managerial practices depend upon many factors (Tosi et al. 1990), such as historic development of the countries, their culture, environmental characteristics (political, social, market, technological), etc. They also relate to the management education implemented in different countries (Byrt 1989) - as results from an international survey carried out in seven countries show. According to them considerable differences exist in the management education and its organisational characteristics, content, educational methods applied, etc. This is mainly due to specifics of the national culture and stage of economic development.

Having in mind the above findings it can be expected that organisational behaviour of managers in Eastern and Central Europe will differ substantially from that of the Western managers. Many authors (Madhavan/ Fogel 1992; Jankovicz/ Pettitt 1993; Perlaki 1993) argue that a key factor to the economic progress in Eastern and Central Europe is education of present and future local managers. They will need a new set of competences and abilities different from those in the period of centrally planned economy. To date, management educational efforts in the former Soviet Block countries have focused on transferring managerial concepts, methods, approaches and practices from Western Europe and the U.S.A. (Fogel 1994). However, it is not clear whether the direct transfer of Western management knowledge and practice has produced effective and efficient results or ever if it is the right approach to the situation. Some authors support the point of view that managerial education across cultures should be adapted to the local requirements, needs and styles in terms of content, training methods, expectations and focus (Thornhill 1993). Therefore, it is likely that the content, approach and emphasis of the managerial education should be consistent with the specifics needs and characteristics of the respective countries. Czako (1992) argues that such an adaptation will create many problems and be difficult for implementation.

It is generally accepted that the basic education in the countries of Eastern and Central Europe is good. For example, the experience from East Germany shows that there is a substantial layer of very well educated persons and qualified professionals. However, management knowledge, thinking and behaviour have been acquired and formed during the system of rigid central planning and control. With the recent moves away from the old dogma, managers in Eastern and Central Europe as a whole are disillusioned and unable to cope under the completely new conditions. A widespread lack of confidence is observed among the managerial strata from the past (Randlesome 1992). The specific management needs of the economies in transition of the countries in Eastern and Central Europe are not well known. This exploratory study is an attempt to contribute to filling in this void. 


\section{Goals of the Study}

\section{Key Questions}

Within the completely new managerial environment of Eastern and Central European countries key questions of managerial needs arise. They are mainly related to the major differences between the practice of management in the former Soviet Block countries and the Western market developed economies. Related to this, is the question of the focus of the methodology. Should management education in these countries focus on traditional functional methodology and content related subjects such as accounting, finance and marketing, or should it focus on effort that develop managers' attitudes, values and beliefs, professional confidence, and ability to cope within the new environmental realities. If some balance could be reached between these two dimensions, what rational proportions could be recommended. Perhaps one of the focuses should be emphasised in the beginning and later the focus can gradually shift. The relative importance of such characteristics as personal development of values, attitudes and beliefs for the effective adoption of functional market-oriented management concepts and methods should be estimated. Key question that follows is what is the relative degree of their significance for the effective implementation of the enhanced accounting, finance and marketing practices.

\section{Purpose}

The purpose of the study is to explore one aspect of the questions outlined above by trying to identify the differences in values and managerial practices among young Bulgarian and U.S. managers. An attempt is made to explore some of the dimensions developed and tested by Bass et al. (1979). These are measures in risk taking, interpersonal competencies related to the approaches used for dealing with the environment; reliance on others; decision making; submissiveness; leadership style; co-operative relations; relevant intelligence; and tolerance for conflict. Our thesis is that if substantial differences exist on these dimensions between Bulgarian and U.S. managers direct U.S. management emphasis may not be efficient and effective in Bulgaria in the short term. Results from previous studies show (Bass et al. 1979; Rosenzweig 1994) that main characteristics of the U.S. management is: high degree of individualism, proactive performance, pragmatism, strong sense for leadership and medium conflict tolerance. To date, no exploratory study of similar type has been carried out with Bulgarian managers. The results of this study can be used by Bulgarian management educators to find rational approach to the management education content according to the contemporary Bulgarian needs. 


\section{Dimensions of Management Behaviour Studied}

A managerial approach which is effective and efficient in one culture may not be so in another. For example, participative leadership style seems to produce effective results in some cultures, but proves to be ineffective in others. It is not suggested that one managerial profile prognosticates success in cross cultural environments. It is argued, however, that in global environment, there appear to be dimensions of management behaviour that are related to successful management across many cultures. This is consistent with the cross cultural studies of Bass et al. (1979) of management characteristics in twelve countries. Some of their dimensions are used as outlined below:

- Risk taking: Risk is involved in most management decisions and is based on achievement motive. Risk taking is common within all cultural contexts, however, degree of risk taking differs.

- Environmental awareness: Environment as defined in this study is immediate internal interpersonal milieu concentrating on the analysis of the respective elements of its objective and psychological specifics. These involve awareness of the feelings of others, accepting comments from others, accepting affection and warmth of others, submissiveness, breadth of focus in problem solving, and awareness of one's own behaviour.

- Reliance on others is the focus on the actual interpersonal relations related to the task completion in actual dependence on higher authority, inventive versus imitative decision making and actual dependence on others.

- Leadership style: Leadership is the degree of ability to influence others to act. It is studied in the aspects of the interpersonal influence among people in the continuous process of their relationships directed towards achieving the objectives of the organisation.

- Relevant intelligence: It relates to the process of managers' information and is analysed on the aspects of objectivity and intuition, and persistence and learning.

- Co-operative relations: They are studied by analysing the mutual relations among peers and subordinates tied to the problem solving and organisational performance.

\section{Study Design}

\section{Measurement}

In order to explore the differences between Bulgarian and U.S. managers a self assessment questionnaire was designed. It was first developed in English, then reviewed and modified to be consistent and usable in Bulgaria and the U.S.A. The questionnaire was translated into Bulgarian and back into English and 
checked by different translators. The measurement instrument is primarily based on scale developed and tested by Bass et al. (1979). The six dimensions were measured with the help of a 37 item paper and pen self-assessment questionnaire. The different dimensions were measured by using the items as follows: for risk taking - four items, for environmental awareness - eleven items, for reliance on others - six items, for leadership style - five items, for relevant intelligence - five items, and for co-operative relations - six items.

\section{Sample and Data Collection}

The questionnaire was administered to a convenience sample of 50 young Bulgarian and 35 U.S. middle level managers. All the American managers were enrolled in MBA courses and all Bulgarian managers attended different master's level business courses. The initial intent was to match the sample to obtain similar demographic characteristics. However, this proved to be difficult to achieve. All respondents that were unemployed were eliminated from the sample. This reduced the sample size to 45 Bulgarian and 33 U.S. respondents.

The demographic characteristics of the two samples can be seen in Table 1 . They are somewhat different. The U.S. respondents tend to be older, work in larger organisations and have more work experience than the Bulgarians. It should be noted that in the U.S. sample 5 managers have worked for very large firms which increased considerably the size of the average work force of the U.S. sample. The Bulgarian sample has larger proportion of females than the U.S. one. The educational backgrounds of the managers from the two samples do not seem to differ substantially. The two samples tend to be different in terms of the industry of the respondents. The Bulgarian sample has a greater variety of industrial backgrounds: agriculture, engineering, education, food processing, health care, manufacturing, and transportation. The U.S. sample has a large contingent from $R \& D$ and engineering. Most of these respondents are employed in high tech electronics industry. The American sample has also several respondents from service industries - finance and accounting, and health care.

The results from this study are exploratory and should be considered in the context of the limitations of the sampling method and the differences in the two samples.

\section{Analysis of the Results}

The usable sample consists of 78 respondents (Bulgaria - N=45, U.S. - N=33). Descriptive breakdowns and simple t-test were calculated for differences in mean values for the two samples. 
Table 1: Sample Characteristics

\begin{tabular}{|lcc|}
\hline & Bulgaria & U.S.A. \\
Sample size (N) & 45 & 33 \\
Age & 26 & 31 \\
Number of employees & & 72 \\
Years of work experience & 4 & 9 \\
Sex: $\quad$ & 26 & 26 \\
Males & 19 & 7 \\
Females & & 10 \\
Education (undergraduate degree): & 9 & 5 \\
Science & 8 & 0 \\
Political science & 2 & 18 \\
Business & 27 & \\
Other & & \\
\hline
\end{tabular}

\section{Risk Taking}

Higher achievement motives are usually associated with higher tendency for risk taking. Moderate risk (Howard 1990) provides challenging and realistic goals. Greater risk requires more incentiveness and inspires it. It involves greater dedication, constantly demands learning new skills and capabilities. The probability of failure increases with any diviation from the moderate risk.

The results from the four items used for the analysis of the risk taking show significant differences in the two samples in three of them (see Fig.1). The U.S. respondents tend to be more willing to trust others than the Bulgarian. This could be explained by the deeply rooted fear among people of Eastern and Central Europe during the totalitarian times when any diviation from the officially enforced doctrine was considered a crime. Therefore it is believed that there has been difference between what people say and what they think and would like to do. This implanted "double facedness" makes managers suspicious to attitudes and decisions assuming high levels of risk. American managers tend to be more willing to take risks under uncertainty. Higher levels of uncertainty are mostly related to the conditions of the environment and content of decisions. Higher level of environmental uncertainty requires more risk in decision making. Unfortunately, lack of experience and the need to perform in a totally new environment creates exorbitant challenges for the Bulgarian managers. They do not know how to deal with them and often prefer to be passive or reactive instead of proactive. Additionally, it is the overall 
collapse of norms, beliefs, relationships, structures and markets that create unprecedented level of uncertainty in which Western management approaches and techniques often prove to be inadequate for solving current problems. Because of these Bulgarian managers sometimes feel helpless and hopeless. Therefore uncertainty coupled with inability to manage independently, as well as lack of sufficient knowledge about the environment, makes Bulgarian managers risk adverse. U.S. managers tend to be much quicker in decision making which can be explained by the above results. The greater speed of decision making among the U.S. managers may be due to the more complete and accurate information availability (Goodman 1993). Management information in Bulgaria can be described as scarce, incomplete and inaccurate. This unfavorably affects the speed of decision making processes. On average, U.S. manager in this sample can be described as a risk taker, while Bulgarian manager can be described as risk adverse. Risk avoidance in decision refers to the extent to which managers wish to have stability and predictability. Bulgarian managers having lived in a society with high uncertainty avoidance (because of the centralised decision making process and social security system guaranteeing average low level living standard) refer more to written regulations and procedures. They have constantly a strong need for consensus, and a permanently high level of anxiety and stress.

Figure 1: Risk Taking

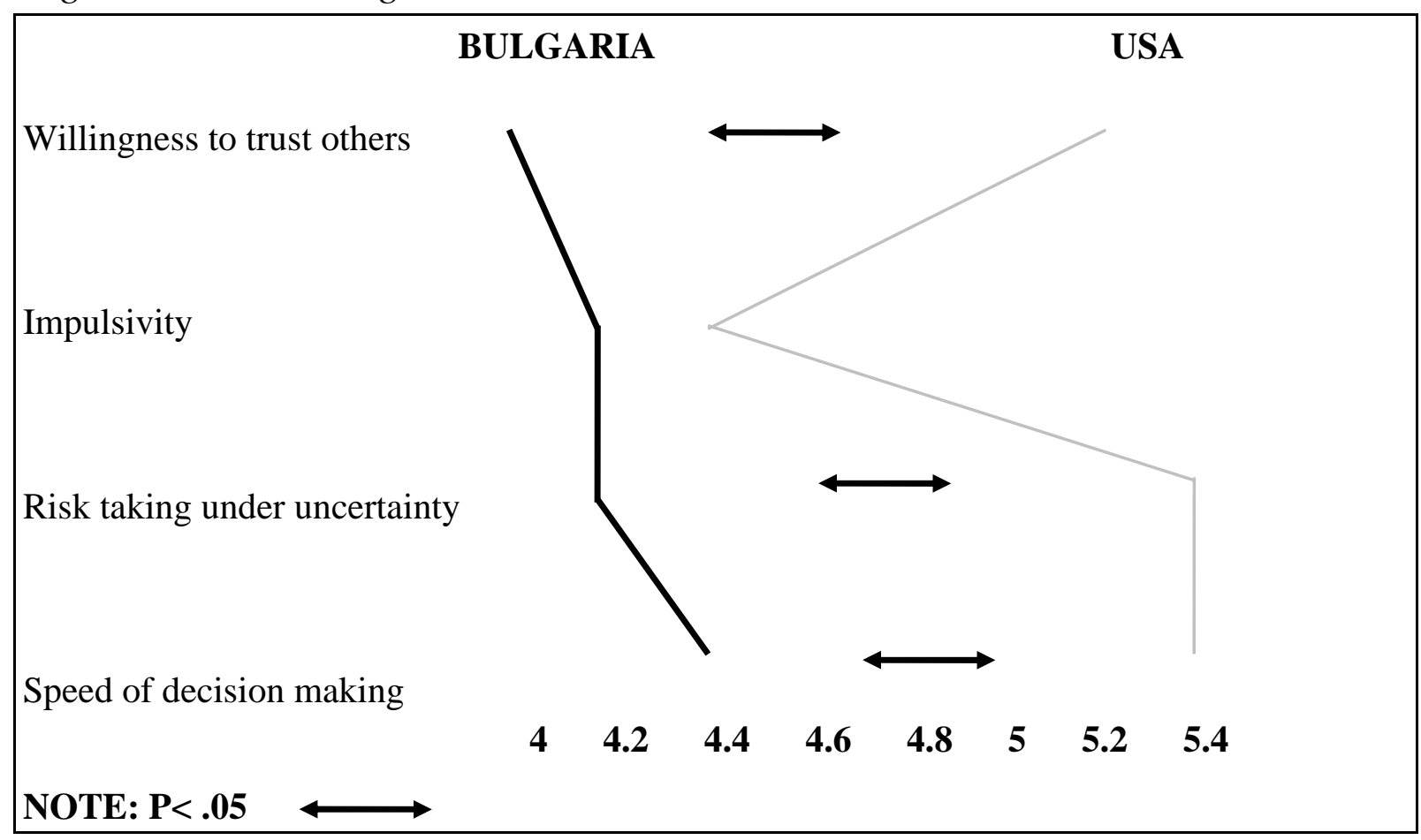

\section{Dealing with the Environment}

The results are presented in Figure 2. From the six items used to study this dimension significant differences are observed in two dimensions. They are: 
"Understand why I do what I do" and "Listen to others with understanding". U.S. managers tend to understand better themselves and their actions and show much more understanding when listening to the others. A possible explanation for these may be the fact that the U.S. environment is more settled than the present Bulgarian one. It can also be added that they have had the opportunity to observe very similar environment their whole lives; to study it and to adapt to it. The volatile characteristics of the contemporary Bulgarian environment, and the risk adverse features of the society can account for the lower level of understanding when Bulgarian managers listen to others. It is also true that managers in Bulgaria for 45 years were appointed by the communist party and they were accountable for their performance only to it. This created a feeling of superiority among managers, alienation and insufficient respect to their subordinates. It was strongly maintained by the highly authoritarian, hierarchical organisational structures. Young Bulgarian managers, on the other hand, tend to ignore existing experience and prefer to "reinvent the wheel" rejecting the reality of yesterday and its managerial practices. Within the organisation one can feel the trend of shift to individualism in management thinking and performance. The results from the U.S. sample may be a consequence of more practical experience and the strong emphasis on rational behaviour and the participative approach in the U.S. business schools.

Figure 2: Dealing with the Environment

Awareness of others' feelings
Anderstand why I do what I do
Accepting comments about behaviour from others to others with understanding
External versus internal focus
NOTE: $\mathbf{P}<\mathbf{. 0 5}$




\section{Reliance on Others}

As seen from Figure 3, significant differences can be observed here in all three items that characterise this dimension. The U.S. sample indicates that, on average American managers rely more on someone at a higher level of authority. They also use an inventive rather than imitative decision approach. Bulgarian managers on the other hand, depend actually more on others. In order to accomplish inventive decision making American managers rely on input from their colleagues. The U.S. results make sense as in the U.S.A. innovative teambased decision making is encouraged, but higher level organisational authorities approve major decisions. In Bulgaria the young manager imitates others rather than thinking of new solutions. This may be a result from the past management culture. Also, in Bulgaria due to more bureaucratic organisations (especially in the state-owned companies), independent decisions may not be scrutinised by superiors as they are in the U.S.A.

Figure 3: Reliance on Others

Actual dependence on higher authority
Intensive versus imitative decision making
Actual dependence on others

\section{Leadership Style}

These results from the study are shown graphically in Figure 4. In a given environment the leadership style is based on organisational culture and personality of manager (Rotemberg/ Salomer 1993; Hughes/ Shackleton 1975) which affects the incentive contracts and concern that managers have with their subordinates. Authoritarian style was the principal characteristic of the leadership in Bulgaria in the recent past. It was based on total obedience and respect from subordinates. As seen from Figure 4, results from the two samples differ significantly in three of the five items used to analyse this dimension. Firstly, in order to obtain results, Bulgarian managers tend to use manipulation, whereas their U.S. colleagues rely more on power for the achievement of results. In contrast to the past Bulgarian communist management practices is the 
practice of "responsibility centre" management in the U.S.A. The American sample shows a "higher concern for subordinates" which is consistent with the above thesis, and higher ability to influence others for which mainly educational content and cultural characteristics may mainly account.

Figure 4: Leadership Style

Use authority to get things done

Manipulation versus power

Concern for welfare of subordinates

Task versus human relations concern

Ability to influence others

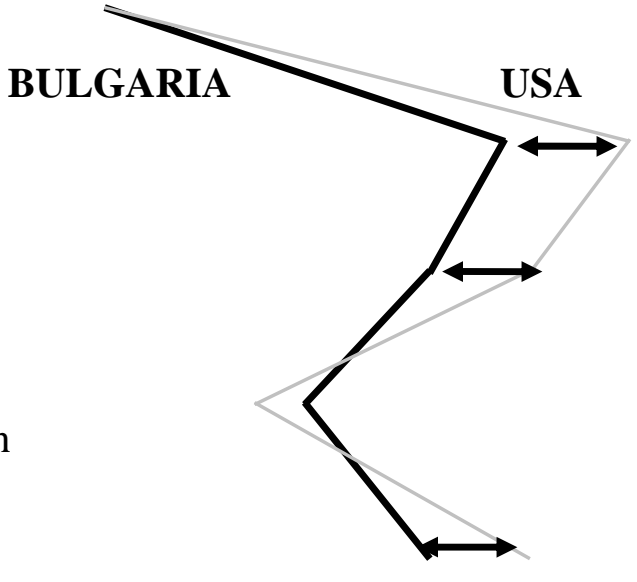

\section{$\begin{array}{lllll}3.2 & 4.2 & 5.2 & 6.2 & 7.2\end{array}$}

NOTE: $\mathbf{P}<.05$

\section{Relevant Intelligence}

In Figure 5, results reflecting the use of relevant information and intelligence are shown. There are no statistical differences between the two samples in terms of using intuition and objectivity. But, the Bulgarian sample indicates less persistence on tough problems and lower tendency to search for learning opportunities. The reason for this can be the existence of bureaucratic predescribed set of procedures which were applied to complex problem solving in the recent past. In addition the rapidly changing global environment in political, economic and organisational aspects faces Bulgarian managers with complicated, complex, unprecedented problems. As a consequence Bulgarian managers often fail to define the core problems and tasks in a concrete situation. These combined with the very limited availability of learning opportunities make things worse for Bulgarian managers. American managers have had for decades a great variety of learning opportunities which form the basis of their innovative business approaches. The findings are also consistent with the American management practice which mostly rewards efforts, diligence and innovative behaviour. Such practices are far from being established in Bulgaria. 
Figure 5: Relevant Intelligence

Objectivity versus intuition

Persistence on tough problems

Searching for learning opportunities



$\begin{array}{llllll}4.5 & 5 & 5.5 & 6 & 6.5 & 7\end{array}$

NOTE: $\mathbf{P}<.05$

\section{Co-operative Relations with Others}

The results, represented in Figure 6, show significant and meaningful differences between the Bulgarian and the U.S. sample. When asked, if they have actual problems in relations with peers, scores show low and no statistical differences between the two samples. However, Bulgarian managers would prefer better relationships with peers and they would like to depend more on others. This relates to the inherited pseudo-collective decision making, existing in the Bulgarian management practices for more than four decades, its core being lack of individual responsibility. The preferred sense of dependability among Bulgarian managers may be a consequence of the "collective" norms of behaviour of the society as a whole and in the business organisations in particular. This may also reflect a desire among Bulgarian managers for enhanced teamwork and co-operative decision making. Further, the U.S. respondents are more willing to discuss their feelings with others, which accounts for an open and a personal style of the average American respondent. Finally, the Bulgarian managers have higher tolerance for conflict. As mentioned above Bulgarians at present live under high constant tension, hence permanent need for consensus exists.

\section{Conclusions and Implications for Research and Management Education}

The results from this study suggest enhancement of the measure and replication of the study with more representative and comparable samples. In spite of the limitations, the findings are interesting and useful observations.

The results in the context of this exploratory study appear to be consistent with the American management customs. When reporting on management practice, on average, the sample of U.S. managers shows propensity to risk taking, 
appear to have high self awareness and demonstrate willingness to listen to others. They value inventive decision making, and depend on others for input. Although the American managers recognise the importance of power, ability to influence others through rational argumentation and concern for the welfare of subordinates are important management traits. Learning and persistence are also relevant management characteristics for them. Compared to Bulgarian managers, American managers have low tolerance for conflict, and they would like to be less dependent on others, but are more willing to discuss their feelings with them.

Figure 6: Cooperative Relation with Others

Actual relations with peers

Preferred relationship with peers

Preferred dependence on others

Willingness to discuss feelings with others

Tolerance for conflict

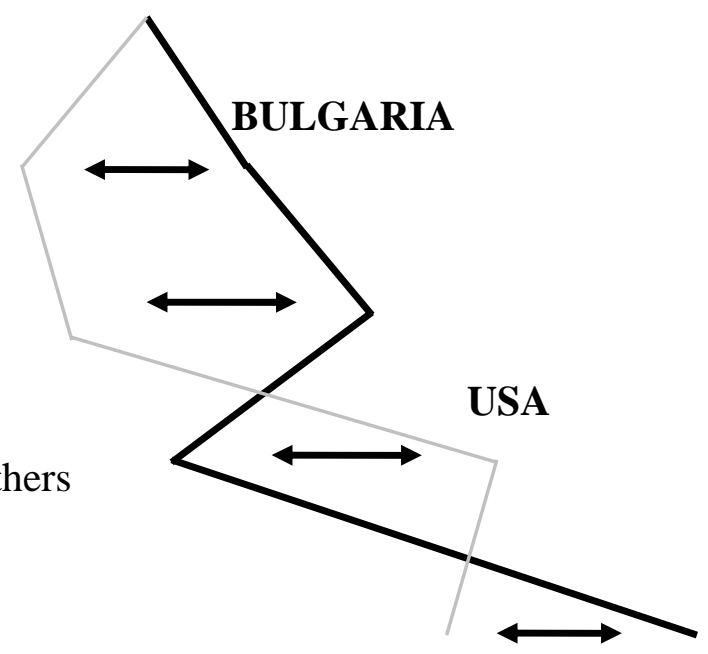

\section{$\begin{array}{llllllll}3.5 & 4 & 4.5 & 5 & 5.5 & 6 & 6.5 & 7\end{array}$}

NOTE: $\mathbf{P}<.05$

In contrast, the Bulgarian managers tend to be risk adverse with slower decision making. They would listen less to others and are less able to explain their own behaviour. They say that they depend less on someone in higher authority, and they depend less on others for input. They also imitate rather than use inventive decision making. Their leadership style tends to apply more manipulation and involves less efforts to influence. Bulgarian managers have also less concern for the welfare of their subordinates. They appear to be less persistent and subsequently less oriented towards learning. However, they demonstrate strong desire for better relationships with peers and preference for dependence on others. Bulgarian managers state their unwillingness to discuss feelings with others and conflict does not seem to have much impact.

Among other problems, the findings raise some principal questions about the future direction of the management education in Bulgaria. It appears that "soft" subjects, such as team building, trust, management by objectives, individual responsibility, contribution and rewards could be important elements in the 
curricula. To accomplish these, management education in Bulgaria must probably move away from the conventional large class lecture format to a format which fosters participation, builds trust and confidence. Case studies and experiential learning might help. The key questions for the long term are: "Will a more participative management style be more effective than the current practice?" and "For those managers that will adopt such approaches, what are their prospects to excel within their organisations?”. Questions of this kind are to be answered by the Bulgarian management educators and the future.

\section{References}

Bass, B.M./ Burger, P.C./ Doktor, R./ Barret, G.V. (1979): Assessing Managers: An International Comparison, New York, The Free Press.

Byrt, W. (ed.) (1989): Management Education: An International Survey, London, Routlege.

Czako, E. (1992): Lessons of the U.S. Business Schools for Hungary: A Comparison, in: Journal of Management Development, Vol. 11, No. 3, pp. 48-55.

Fogel, D.S. (1994): Managing in Emerging Market Economies: Cases from the Czech and Slovak Republics, San Francisco, Westview Press, pp. 130-145.

Goodman, S.K. (1993): Information Needs for Management Decision Making, in: Records Management Quarterly, Vol. 27, No. 4, pp. 12-23.

Howard, J.P. (1990): Moderate Risk: Key to Professional Success, in: Supervisory Management, Vol. 35, No. 11, pp. 1-2.

Hughes, R./ Shackleton, V. (1975): Leadership Styles, in: New Behaviour, 11 September, pp. 421-423.

Jankowick, D./ Pettitt, S. (1993): Words in Collusion: An Analysis of an Eastern European Management Development Initiative, in: Management Education \& Development, Vol. 24, No.1, pp. 93-104.

Madhavan, R./ Fogel, D.S. (1992): In Support of Reform: Western Business Education in Central and Eastern Europe, in: Review of Business, Vol. 13, No. 4, pp 4-9.

Perlaki, I. (1993): Management Development for Eastern Europe, in: Multinational Business Review, Vol. 1, No. 1, pp. 10-18.

Randlesome, C. (1992): East German Managers: From Karl Marx to Adam Smith, in: European Management Journal, Vol. 10, No. 1, pp. 74-79.

Rosenzweig, P. (1994): Why Is Management in the United States So Difficult for European Firms?, in: European Management Journal, Vol. 12, No. 1, pp. 31-38.

Rotenberg, J.J./ Daloner, G. (1993): Leadership Style and Incentives, in: Management Science, Vol. 39, No. 11, pp. 1299-1318.

Thornhill, A.R. (1993): Management Training Across Cultures: The Challenge for Trainers, in: Journal of European Industrial Training, Vol. 17, No. 10, pp. 43-51.

Tosi, H.L./ Rizzo, J.R./ Carroll, S.J. (1990): Managing Organizational Behavior, 2nd edition, New York, Harper \& Row. 